\title{
A Statistical Approach to Safety Margin Evaluation of Irradiation Experiments in the ATR
}

\author{
Paul E. Murray
}

December 2018

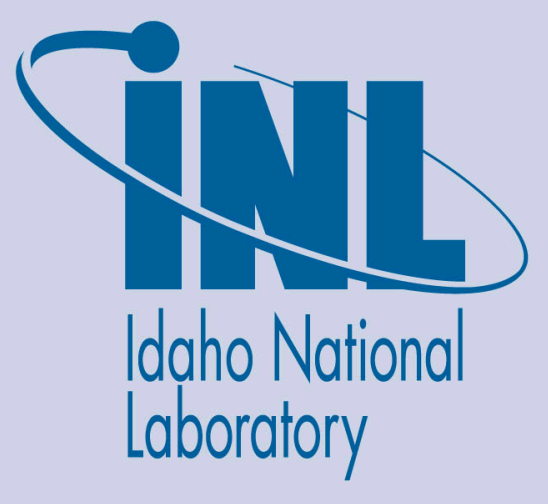

The INL is a U.S. Department of Energy National Laboratory operated by Battelle Energy Alliance 


\section{DISCLAIMER}

This information was prepared as an account of work sponsored by an agency of the U.S. Government. Neither the U.S. Government nor any agency thereof, nor any of their employees, makes any warranty, expressed or implied, or assumes any legal liability or responsibility for the accuracy, completeness, or usefulness, of any information, apparatus, product, or process disclosed, or represents that its use would not infringe privately owned rights. References herein to any specific commercial product, process, or service by trade name, trade mark, manufacturer, or otherwise, does not necessarily constitute or imply its endorsement, recommendation, or favoring by the U.S. Government or any agency thereof. The views and opinions of authors expressed herein do not necessarily state or reflect those of the U.S. Government or any agency thereof. 


\title{
A Statistical Approach to Safety Margin Evaluation of Irradiation Experiments in the ATR
}

\author{
Paul E. Murray
}

December 2018

Idaho National Laboratory

Nuclear Science and Technology

Idaho Falls, Idaho 83415

http://www.inl.gov

Prepared for the

U.S. Department of Energy

Office of Nuclear Energy

Under DOE Idaho Operations Office

Contract DE-AC07-05ID14517 

Nuclear Science and Technology

\section{A Statistical Approach to Safety Margin Evaluation of Irradiation Experiments in the ATR}

INL/EXT-18-52054

December 2018

Approved by:

Paul Murray

Thermal Hydraulic Analyst

Joseph Nielsen

Reactor Physics Analyst

Ryan Marlow

Experiment Safety Analyst

Misti Lillo

Manager
Date

Date

\section{Date}




\begin{abstract}
The current safety basis of the INL Advanced Test Reactor requires that irradiation experiments meet minimum safety margins to critical heat flux and flow instability during anticipated reactor fault conditions. Compliance to these requirements may be demonstrated by calculating safety margins using safety factors that account for uncertainties, or using a statistical approach to quantify the uncertainty in the safety margins. Safety margins obtained from the first approach are conservative since the individual events leading to the cumulative safety factor are assumed to occur simultaneously at their maximum uncertainty. The statistical approach is less conservative in the case where the uncertainties are not too large, and may reduce the conservatism resulting from an overabundance of safety factors. This report describes the procedure for safety margin evaluation using a statistical approach and identifies the important thermal-hydraulic variables to consider in an uncertainty analysis. In particular, safety margins to critical heat flux and flow instability are evaluated for three recent high power fueled experiments (MP-1, FSP-1 and AFIP-6) using RELAP5 coupled to RAVEN to perform statistical analysis and uncertainty quantification. The results demonstrate adequate safety margins to critical heat flux and flow instability during an anticipated loss of commercial power to the reactor.
\end{abstract}




\section{CONTENTS}

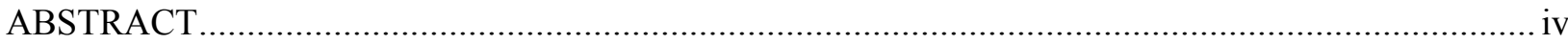

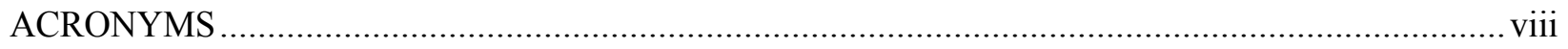

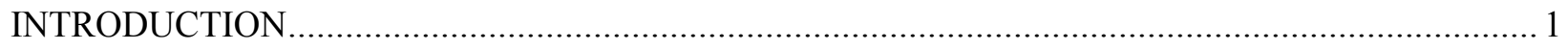

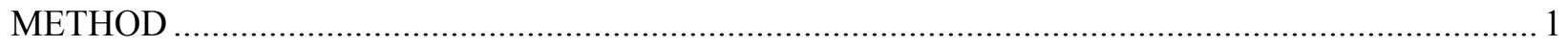

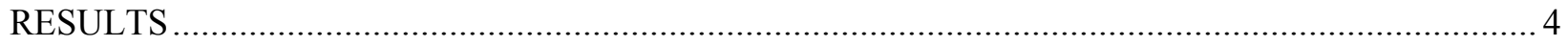

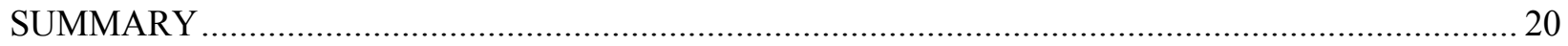

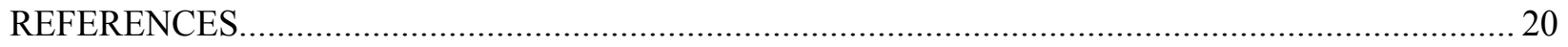

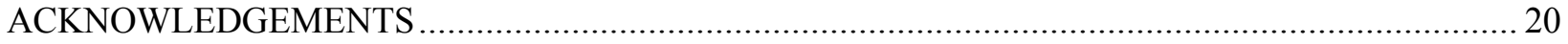

\section{FIGURES}

Figure 1. Time History of the Mean Value of DNBR in the MP-1 experiment. .....................................5

Figure 2. Histogram of DNBR at the Time of Minimum DNBR in the MP-1 experiment. ...................... 6

Figure 3. Time History of the Mean Value of FIR in the MP-1 experiment........................................ 7

Figure 4. Histogram of FIR at the Time of Minimum FIR in the MP-1 experiment.............................. 8

Figure 5. Time History of the Mean Value of DNBR in the FSP-1 experiment. ................................... 10

Figure 6. Histogram of DNBR at the Time of Minimum DNBR in the FSP-1 experiment..................... 11

Figure 7. Time History of the Mean Value of FIR in the FSP-1 experiment....................................... 12

Figure 8. Histogram of FIR at the Time of Minimum FIR in the FSP-1 experiment............................. 13

Figure 9. Time History of the Mean Value of DNBR in the AFIP-6 experiment. ................................. 15

Figure 10. Histogram of DNBR at the Time of Minimum DNBR in the AFIP-6 experiment.................. 16

Figure 11. Time History of the Mean Value of FIR in the AFIP-6 experiment. ................................... 17

Figure 12. Histogram of FIR at the Time of Minimum FIR in the AFIP-6 experiment. ........................ 18

\section{TABLES}

Table 1. Statistical Analysis of the Output Parameters in the MP-1 experiment. .................................... 9

Table 2. Statistical Analysis of the Output Parameters in the FSP-1 experiment. .................................. 14

Table 3. Statistical Analysis of the Output Parameters in the AFIP-6 experiment. ................................ 19 


\section{ACRONYMS}

AFIP-6

ATR

CHF

DNB

DNBR

FI

FIR

FSP-1

MP-1

RAVEN

RELAP5
ATR Full Size Plate in Center Flux Trap Position - Experiment No. 6

Advanced Test Reactor

Critical Heat Flux

Departure from Nucleate Boiling

DNB Ratio

Flow Instability

FI Ratio

Full Size Plate - Experiment No. 1

Mini Plate - Experiment No. 1

Risk Analysis Virtual Environment

Reactor Excursion and Leak Analysis Program 


\section{A Statistical Approach to Safety Margin Evaluation of Irradiation Experiments in the ATR INTRODUCTION}

The current safety basis of the INL Advanced Test Reactor requires that irradiation experiments meet minimum safety margins to critical heat flux and flow instability during anticipated reactor fault conditions. In most cases, compliance to these requirements is demonstrated by showing that the safety margins exceed a value of two at the maximum experiment heat flux. However, this approach has limited the heat flux attained during irradiation of fueled experiments since a minimum safety margin of two may not be met at high heat flux. The current safety basis allows the use of statistical analysis of uncertainties to demonstrate compliance to minimum safety margins to critical heat flux and flow instability. In particular, compliance may be demonstrated by showing that the critical heat flux is three standard deviations greater than the mean value of the peak heat flux, and the temperature rise to saturation is three standard deviations greater than the mean value of the peak temperature rise along the experiment. The statistical criteria are less conservative in the case where the uncertainties are not too large. Therefore, using a statistical approach to quantify the uncertainty in safety margins rather than using fixed safety factors to account for the maximum uncertainty will enable irradiation of fueled experiments at higher heat flux.

The INL has developed software that may be used to evaluate safety margins using statistical analysis. This includes RELAP5, a thermal-hydraulic systems analysis software designed to simulate accident conditions in nuclear reactors, and RAVEN, a multi-purpose software framework for performing statistical analysis and uncertainty quantification. In this report, safety margins to critical heat flux and flow instability are evaluated for three recent high power fueled experiments (MP-1, FSP-1 and AFIP-6) using RELAP5 coupled to RAVEN. The results demonstrate adequate safety margins to critical heat flux and flow instability during an anticipated loss of commercial power to the reactor. Moreover, this report describes the procedure for performing a statistical approach to safety margin evaluation and identifies the important thermal-hydraulic variables to consider in an uncertainty analysis.

\section{METHOD}

The safety basis of the INL Advanced Test Reactor requires that, in the event of a loss of commercial power resulting in coast-down of the coolant pumps, the safety margins to critical heat flux (CHF) and flow instability (FI) be greater than two at the surfaces of an experiment in contact with reactor coolant (SAR-153, Section 10.3.5.2.1). These conditions are concisely given in terms of the DNB ratio (DNBR) and FI ratio (FIR):

$$
\begin{aligned}
& D N B R=\frac{q_{\text {chf }}}{q_{\max }} \geq 2 \\
& F I R=\frac{\Delta T_{\text {sat }}}{\Delta T_{\max }} \geq 2
\end{aligned}
$$

In equation (1), $q_{c h f}$ is the critical heat flux and $q_{\max }$ is the maximum heat flux at surfaces contacting primary coolant. In equation (2), $\Delta T_{\text {sat }}$ is the temperature rise to saturation and $\Delta T_{\max }$ 
is the temperature rise of the primary coolant from the inlet to the outlet of the coolant channel. The variable $\Delta T_{\text {sat }}$ is given by

$$
\Delta T_{\text {sat }}=T_{\text {sat }}-T_{\text {inlet }}
$$

The variable $T_{\text {sat }}$ is the primary coolant saturation temperature and $T_{\text {inlet }}$ is the primary coolant temperature at the inlet to the coolant channel.

Equations (1) and (2) specify a minimum safety margin to CHF and FI equal to two. This includes safety factors that account for uncertainties in reactor power, experiment heating rate, coolant flow through the experiment, convective heat transfer coefficient, and critical heat flux. Moreover, the flow coast-down event is usually combined with assumptions that envelope all anticipated reactor operating conditions. For example, it is usually assumed that a flow coastdown event occurs when the reactor lobe power is at its maximum allowable value, the actual lobe power exceeds indicated lobe power by the maximum value of the measurement error, fissile material loading is at its maximum value, and the shims are at the fully withdrawn position leading to a high neutron flux in the reflector. These simultaneous events have a lower probability of occurrence and so the resulting safety margins may be more conservative than needed to meet ATR safety requirements. This approach to safety analysis may limit the ability to irradiate high power fuel experiments in the ATR since the minimum required safety margins may not be met at high experiment power.

A statistical approach to safety margin evaluation is allowed by the ATR safety basis. This approach is based on an analysis of the uncertainties associated with the calculated values of heat flux and coolant temperature rise. In this case, it is assumed that the heat flux and coolant temperature rise are random variables having a normal distribution. The critical heat flux must be at least three standard deviations greater than the expected value of maximum heat flux, and the temperature rise to saturation must be at least three standard deviations greater than the expected value of the maximum temperature rise of the coolant:

$$
\begin{aligned}
& \overline{q_{\max }}+3 \sigma_{q} \leq q_{\text {chf }} \\
& \overline{\Delta T_{\max }}+3 \sigma_{\Delta T} \leq \Delta T_{\text {sat }}
\end{aligned}
$$

In equations (4) and (5), $\sigma_{q}$ is the standard deviation of the probability distribution of maximum heat flux, and $\sigma_{\Delta T}$ is the standard deviation of the probability distribution of the maximum coolant temperature rise. Note that the statistical method requires an uncertainty analysis to estimate the standard deviation of the probability distributions. The statistical criteria are less conservative in the case where the uncertainties are not too large.

Three ATR irradiation experiments were selected as test cases to evaluate thermal-hydraulic safety margins using the statistical method. These include the MP-1 mini-plate experiment (ECAR-2975), the FSP-1 full-size-plate experiment (ECAR-2677) and the AFIP-6 full-size-plate experiment (ECAR-1641). Each of these experiments are used to test aluminum-clad U-Mo fuel plates at high values of fuel plate heat flux. In these cases, the minimum safety margins to DNB and FI are sometimes less than the limiting value of two when using safety factors to account for uncertainties. Therefore, an uncertainty analysis of thermal-hydraulic safety margins was performed to show that the statistical criteria for DNB and FI safety margins are met in the three 
test cases. Safety margin evaluation using uncertainty analysis reduces the conservatism resulting from an overabundance of safety factors. This will expand the safe operating envelope of ATR experiments and allow testing of high heat flux fuel plates.

The uncertainty analysis of safety margins was performed using RAVEN coupled with RELAP5. RELAP5 is a thermal-hydraulic systems analysis software that is designed to simulate accident conditions in nuclear reactors. RAVEN is a multi-purpose software framework for performing statistical analysis and uncertainty quantification. RAVEN contains application programming interfaces to interact with complex system analysis software such as RELAP5. The response of the RELAP5 output space is explored by perturbing the RELAP5 input space using various probability distributions and sampling methods defined in RAVEN.

RELAP5 was used to simulate a loss of commercial power resulting in coast-down of the coolant pumps. In this event, the reactor scrams at low vessel inlet pressure at approximately one second after the loss of power. Coolant flow and pressure decrease during the transient, while reactor power increases prior to scram due to coast-down of the loop pumps and voiding of the loops. The flow coast-down transient is analyzed to determine the time at which the safety margins are a minimum. In the three test cases, minimum safety margins occur at the instant of scram when reactor power is $123 \%$ of its initial value, coolant flow is $77 \%$ of its initial value, inlet coolant pressure is $85 \%$ of its initial value, and coolant pressure drop is $59 \%$ of its initial value (see ECAR-3078).

All variables used to calculate safety margins to DNB and FI are obtained from the RELAP5 analysis. The safety margins are defined in equations (1) and (2) given above. The critical heat flux (CHF) is obtained from the 2006 CHF lookup table developed by Groeneveld et al. (2007):

$$
q_{c h f}=q_{c h f_{-} L U T}\left(\frac{8 m m}{D}\right)^{0.33} e^{\frac{D}{L}}
$$

In equation (6), $q_{\text {chf_LUT }}$ is the critical heat flux that is obtained from the lookup table using linear interpolation, $D$ is the hydraulic diameter and $L$ is the heated length of the channel. The table value depends on the coolant mass flux, pressure and thermodynamic quality. The second and third terms are adjustment factors that account for the diameter and heated length effects.

The parameters in the RELAP5 input space include the power factor, inlet coolant pressure during the transient, hydraulic diameter and flow area of each channel. The power factor accounts for numerous variables that effect the power in the fuel plates. Fixed power factors include the maximum reactor over-power, shims fully withdrawn, and a hot channel factor representing the ratio of the maximum fuel plate heat flux to the average fuel plate heat flux. Variable power factors include power measurement uncertainty and fuel loading variability. Parameters in the RELAP5 output space that are used in the calculation of DNBR include mass flux, pressure, quality, heat flux and critical heat flux. Parameters in the RELAP5 output space that are used in the calculation of FIR include coolant temperature and saturation temperature. The cladding temperature is also included in the RELAP5 output space.

Each irradiation experiment is unique from the standpoint of uncertainty quantification. In this study, a normal distribution of the input parameters is assumed which is defined by the mean $(\mu)$ and standard deviation $(\sigma)$ of the distribution. The values of the ratio $\sigma / \mu$ used in this study are 
similar to those used in the safety analysis of ATR driver fuel (TRA-ATR-840): $\sigma / \mu=0.0425$ for reactor power measurement, $\sigma / \mu=0.075$ for fuel loading, $\sigma / \mu=0.025$ for inlet pressure, $\sigma / \mu=0.048$ for hydraulic diameter, and $\sigma / \mu=0.025$ for flow area. The fixed over-power factor is experiment-specific and must accommodate the maximum allowable variation in reactor power. The fixed shim factor is position-dependent and is largest for positions adjacent to the outer shim control cylinders. The fixed hot channel factor is also experiment-specific and depends on the geometry of the fuel plate.

In the RAVEN analysis, the input parameters are sampled using either the Monte Carlo method or the Latin Hypercube method. The latter method has the advantage of requiring less samples to converge. In the case of the Latin Hypercube method, 500 samples are generated according to the assumed probability distribution. The response of the output parameters is determined by calculating the mean and standard deviation of each parameter.

\section{RESULTS}

Selected results from the MP-1 experiment are shown in Figures 1 through 4. These include the time histories and histograms of DNBR and FIR during a flow coast-down event. Note that the minimum values of DNBR and FIR occur at approximately one second after the start of the flow coast-down transient which coincides with the reactor scram. A summary of the statistical analysis of the output parameters from the MP-1 experiment is shown in Table 1. Similar results from the FSP-1 and AFIP-6 experiments are shown in Figures 5 through 12 and Tables 2 and 3.

In each case, the statistical criteria for DNBR and FIR given by equations (4) and (5) are met. The results are shown below, assuming $T_{\text {inlet }}=325 \mathrm{~K}$.

For MP-1,

$$
\begin{array}{lll}
\overline{q_{\max }}+3 \sigma_{q}=13.9 \frac{M W}{m^{2}} & q_{c h f}=24.8 \frac{M W}{m^{2}} & \frac{\overline{q_{\max }}+3 \sigma_{q}}{q_{c h f}}=0.56<1.0 \\
\overline{\Delta T_{\max }}+3 \sigma_{\Delta T}=45^{\circ} \mathrm{C} & \Delta T_{\text {sat }}=161^{\circ} \mathrm{C} & \frac{\overline{\Delta T_{\max }}+3 \sigma_{\Delta T}}{\Delta T_{\text {sat }}}=0.28<1.0
\end{array}
$$

For FSP-1,

$$
\begin{array}{lll}
\overline{q_{\text {max }}}+3 \sigma_{q}=9.0 \frac{\mathrm{MW}}{\mathrm{m}^{2}} & q_{c h f}=20.2 \frac{\mathrm{MW}}{\mathrm{m}^{2}} & \frac{\overline{q_{\text {max }}}+3 \sigma_{q}}{q_{c h f}}=0.45<1.0 \\
\overline{\Delta T_{\text {max }}}+3 \sigma_{\Delta T}=64^{\circ} \mathrm{C} & \Delta T_{\text {sat }}=158^{\circ} \mathrm{C} & \frac{\overline{\Delta T_{\text {max }}}+3 \sigma_{\Delta T}}{\Delta T_{\text {sat }}}=0.41<1.0
\end{array}
$$

For AFIP-6,

$$
\begin{array}{lll}
\overline{q_{\max }}+3 \sigma_{q}=13.2 \frac{M W}{m^{2}} & q_{c h f}=37.1 \frac{M W}{m^{2}} & \frac{\overline{q_{\max }}+3 \sigma_{q}}{q_{c h f}}=0.36<1.0 \\
\overline{\Delta T_{\max }}+3 \sigma_{\Delta T}=19^{\circ} \mathrm{C} & \Delta T_{\text {sat }}=157^{\circ} \mathrm{C} & \frac{\overline{\Delta T_{\max }}+3 \sigma_{\Delta T}}{\Delta T_{\text {sat }}}=0.12<1.0
\end{array}
$$




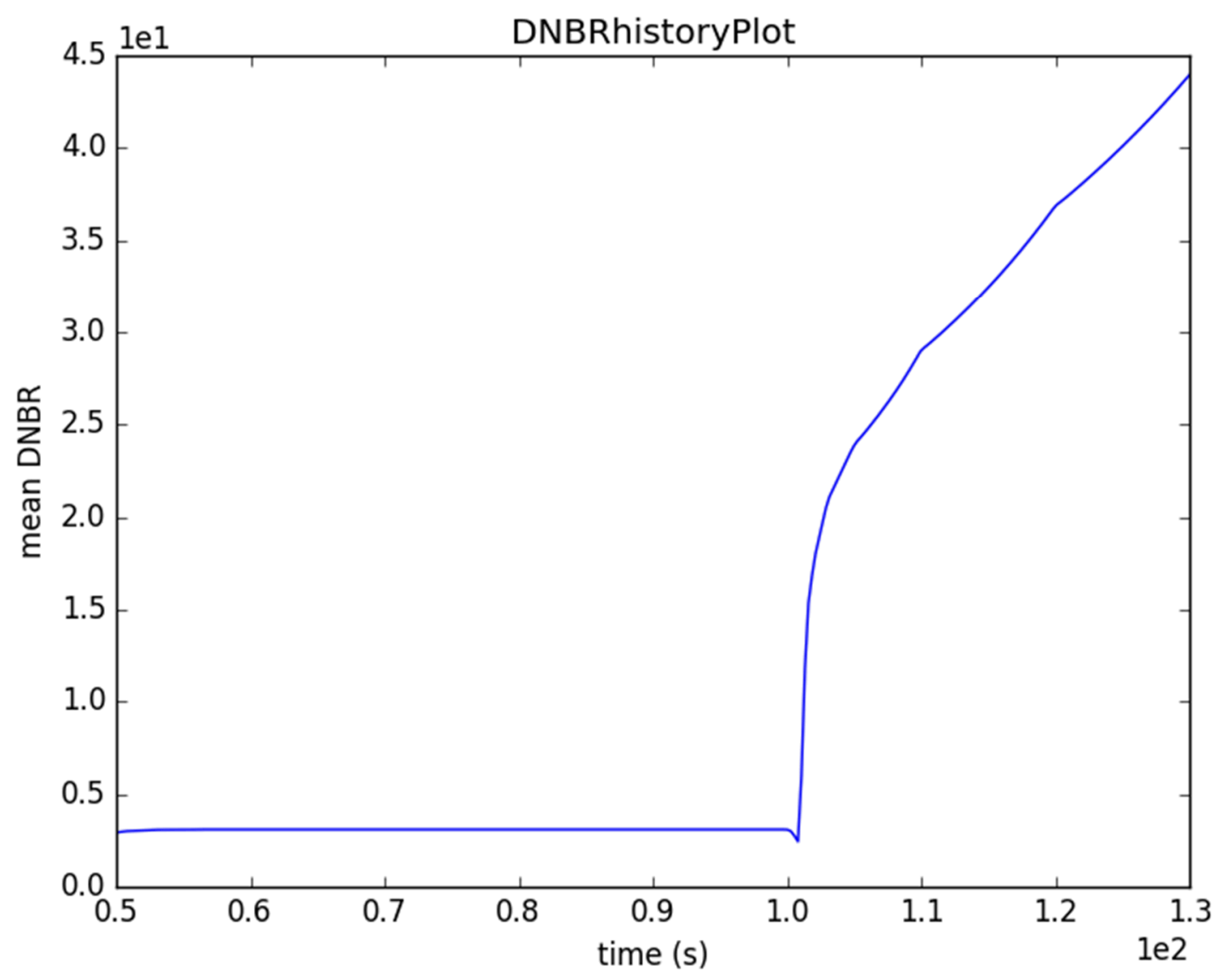

Figure 1. Time History of the Mean Value of DNBR in the MP-1 experiment. 


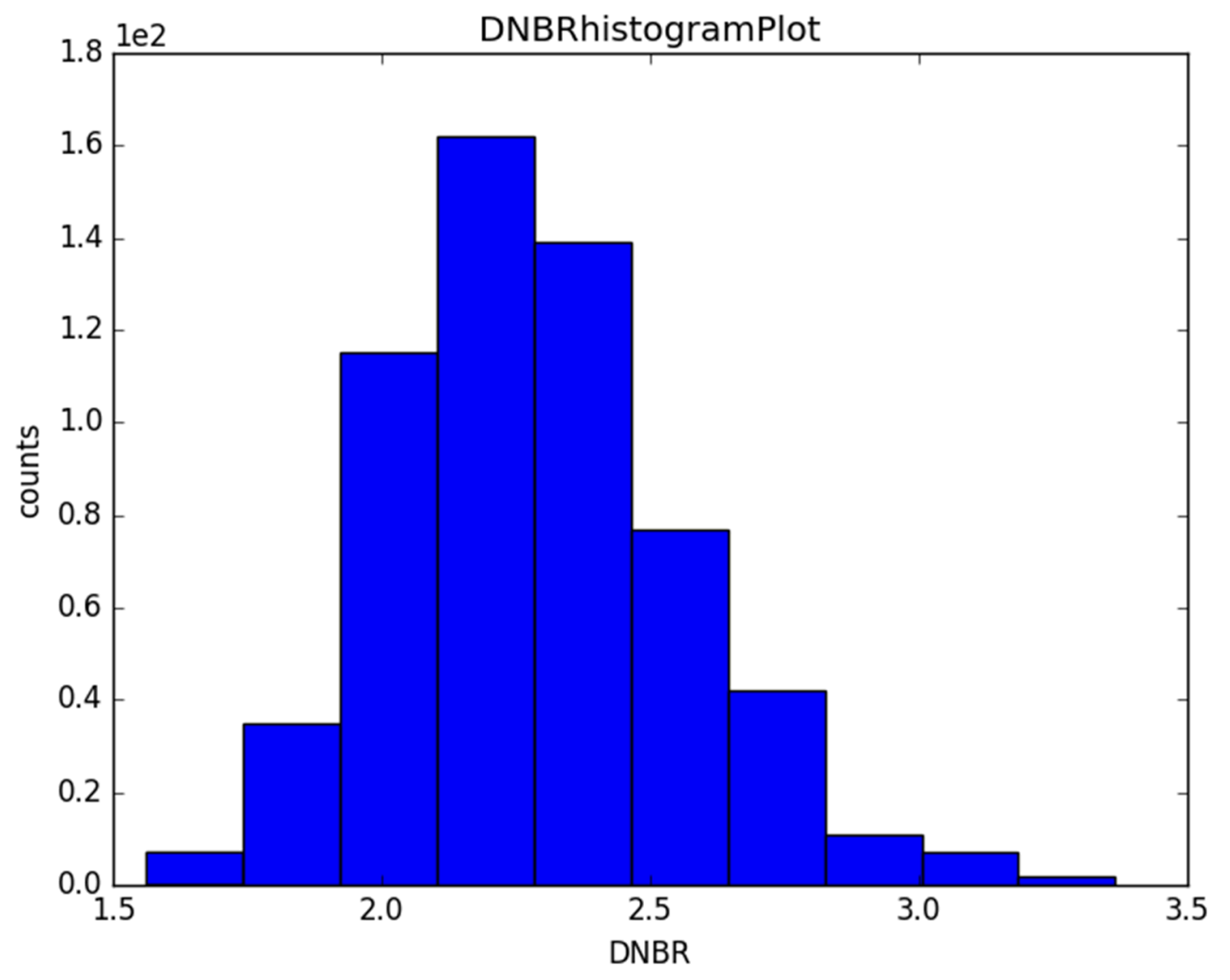

Figure 2. Histogram of DNBR at the Time of Minimum DNBR in the MP-1 experiment. 


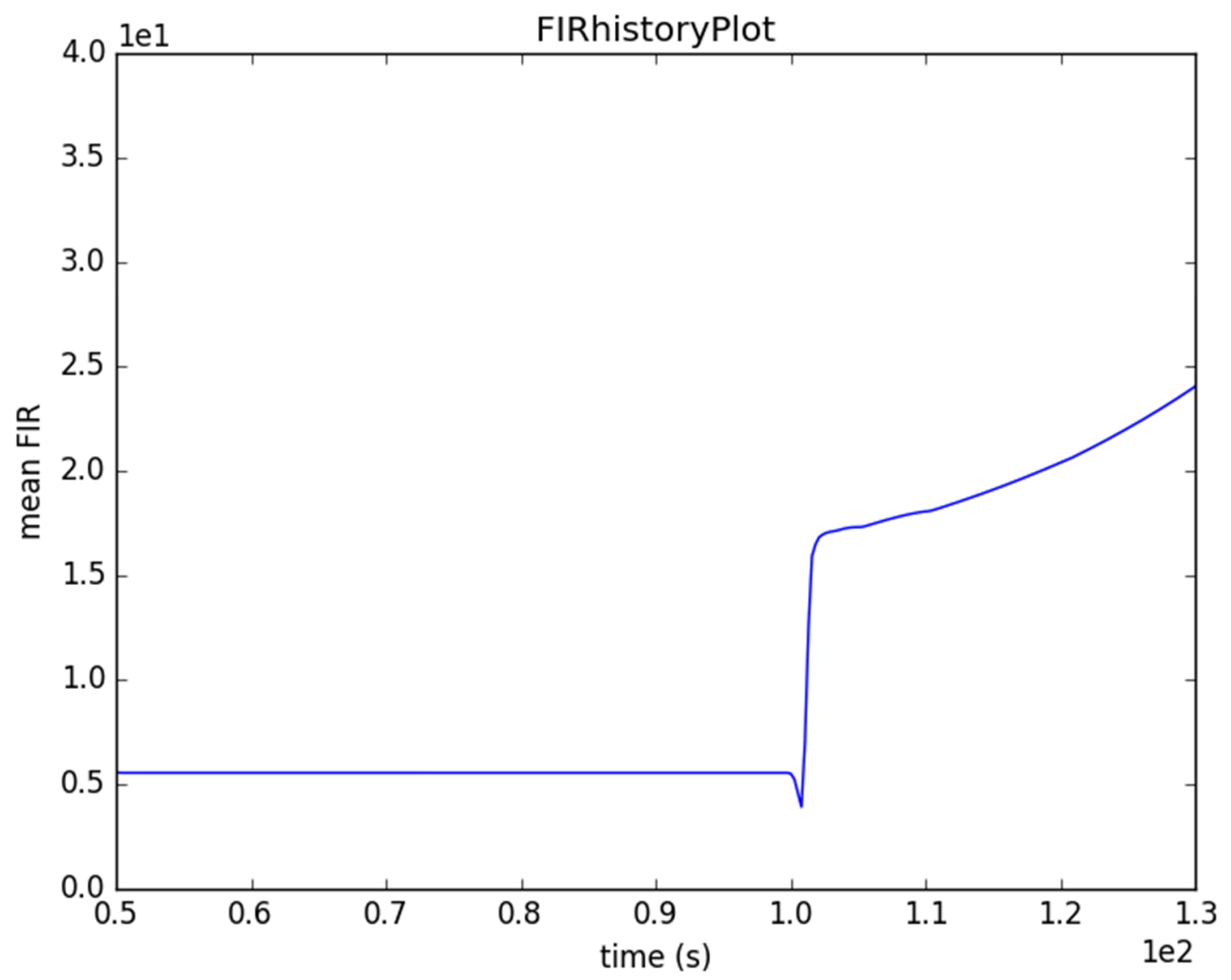

Figure 3. Time History of the Mean Value of FIR in the MP-1 experiment. 


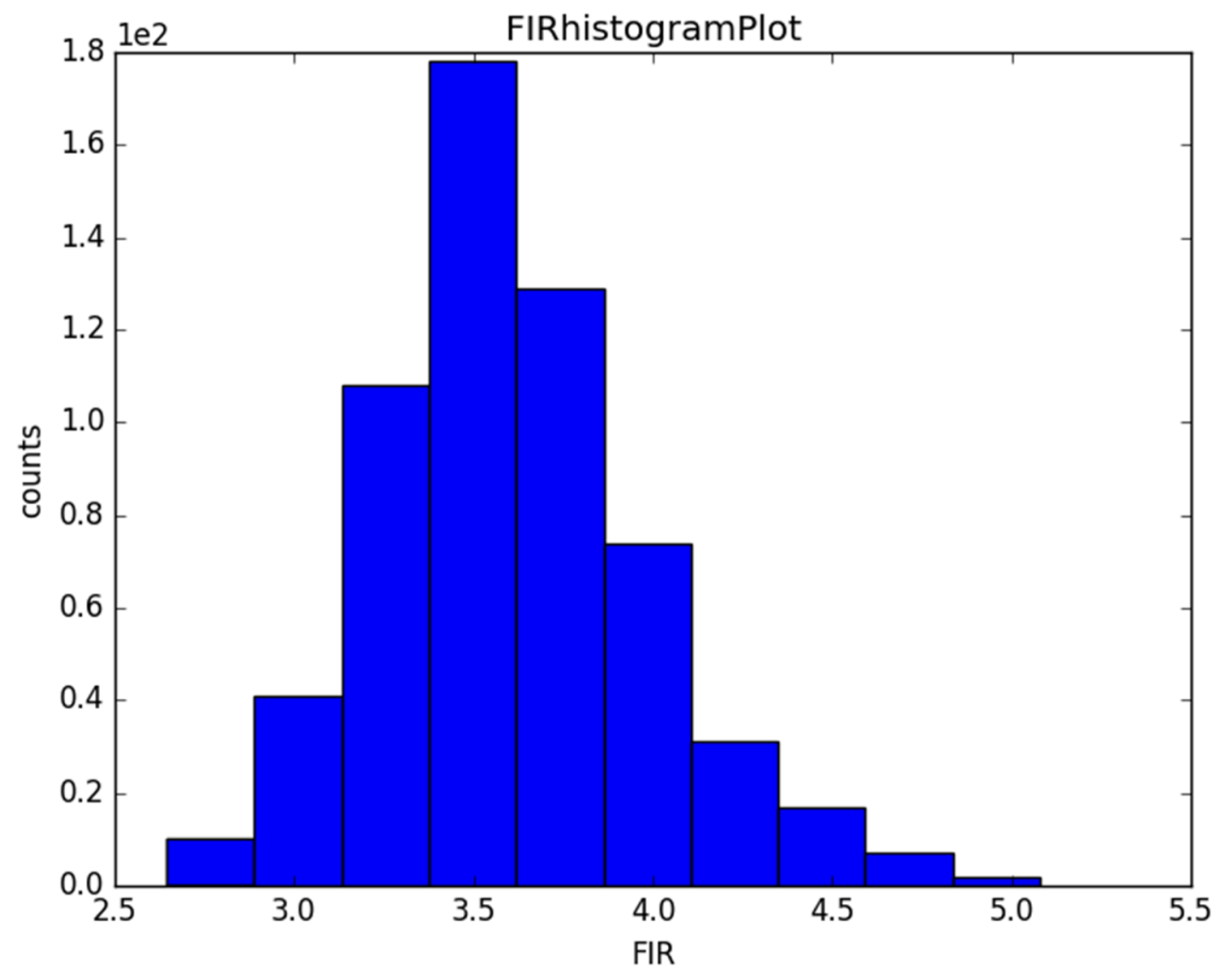

Figure 4. Histogram of FIR at the Time of Minimum FIR in the MP-1 experiment 
Table 1. Statistical Analysis of the Output Parameters in the MP-1 experiment.

\begin{tabular}{|l|l|l|}
\hline Parameter & Mean & $\begin{array}{l}\text { Standard } \\
\text { Deviation }\end{array}$ \\
\hline mass flux $(\mathrm{kg} / \mathrm{s})$ & 0.680 & 0.0362 \\
\hline pressure $(\mathrm{MPa})$ & 2.02 & 0.0135 \\
\hline quality & -0.268 & 0.0107 \\
\hline heat flux $\left(\mathrm{MW} / \mathrm{m}^{2}\right)$ & 11.0 & 0.962 \\
\hline cladding temperature $\left({ }^{\circ} \mathrm{K}\right)$ & 512 & 8.96 \\
\hline CHF $\left(\mathrm{MW} / \mathrm{m}^{2}\right)$ & 24.8 & 0.866 \\
\hline DNBR & 2.29 & 0.273 \\
\hline coolant temperature $\left({ }^{\circ} \mathrm{K}\right)$ & 370 & 4.59 \\
\hline saturation temperature $\left({ }^{\circ} \mathrm{K}\right)$ & 486 & 0.334 \\
\hline FIR & 3.60 & 0.377 \\
\hline
\end{tabular}




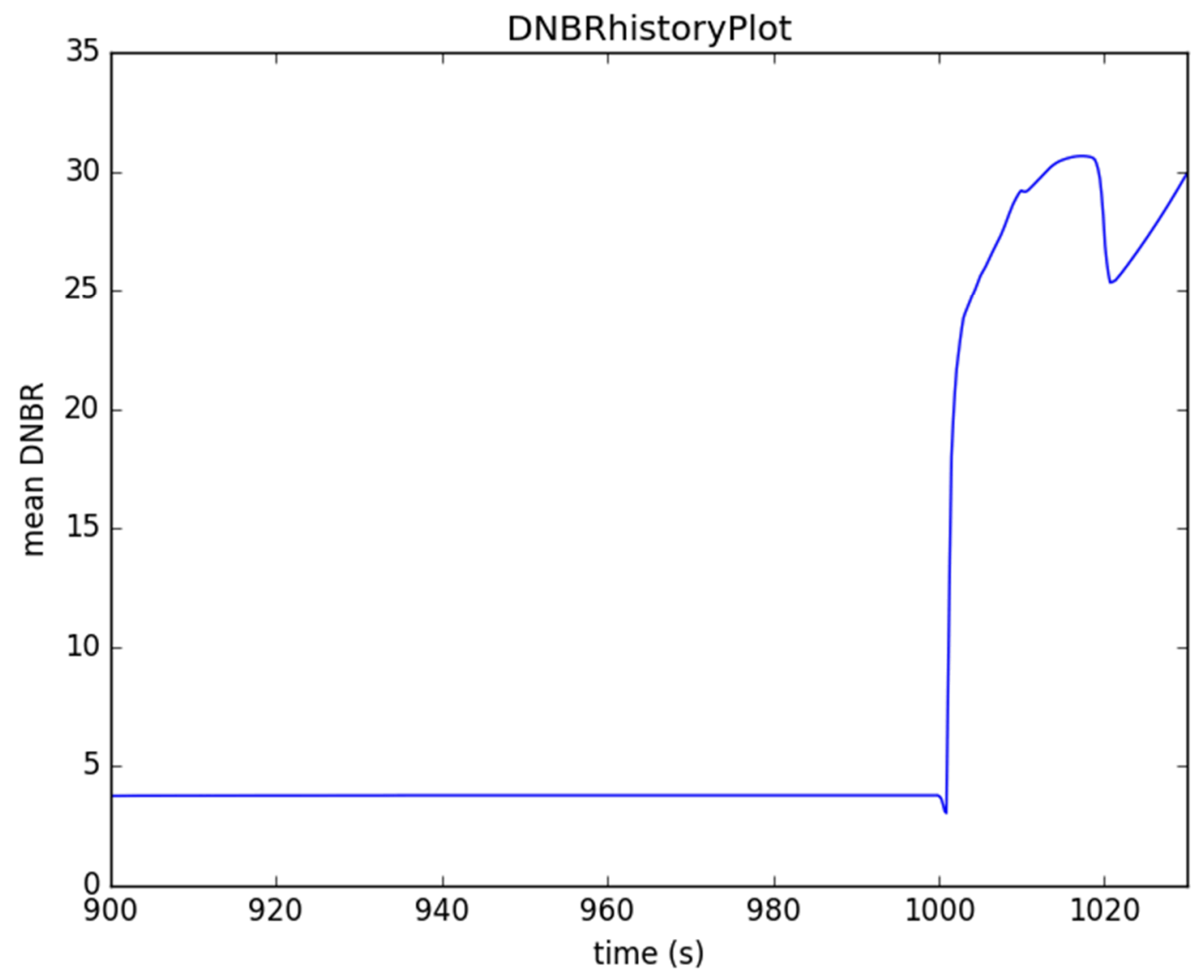

Figure 5. Time History of the Mean Value of DNBR in the FSP-1 experiment. 


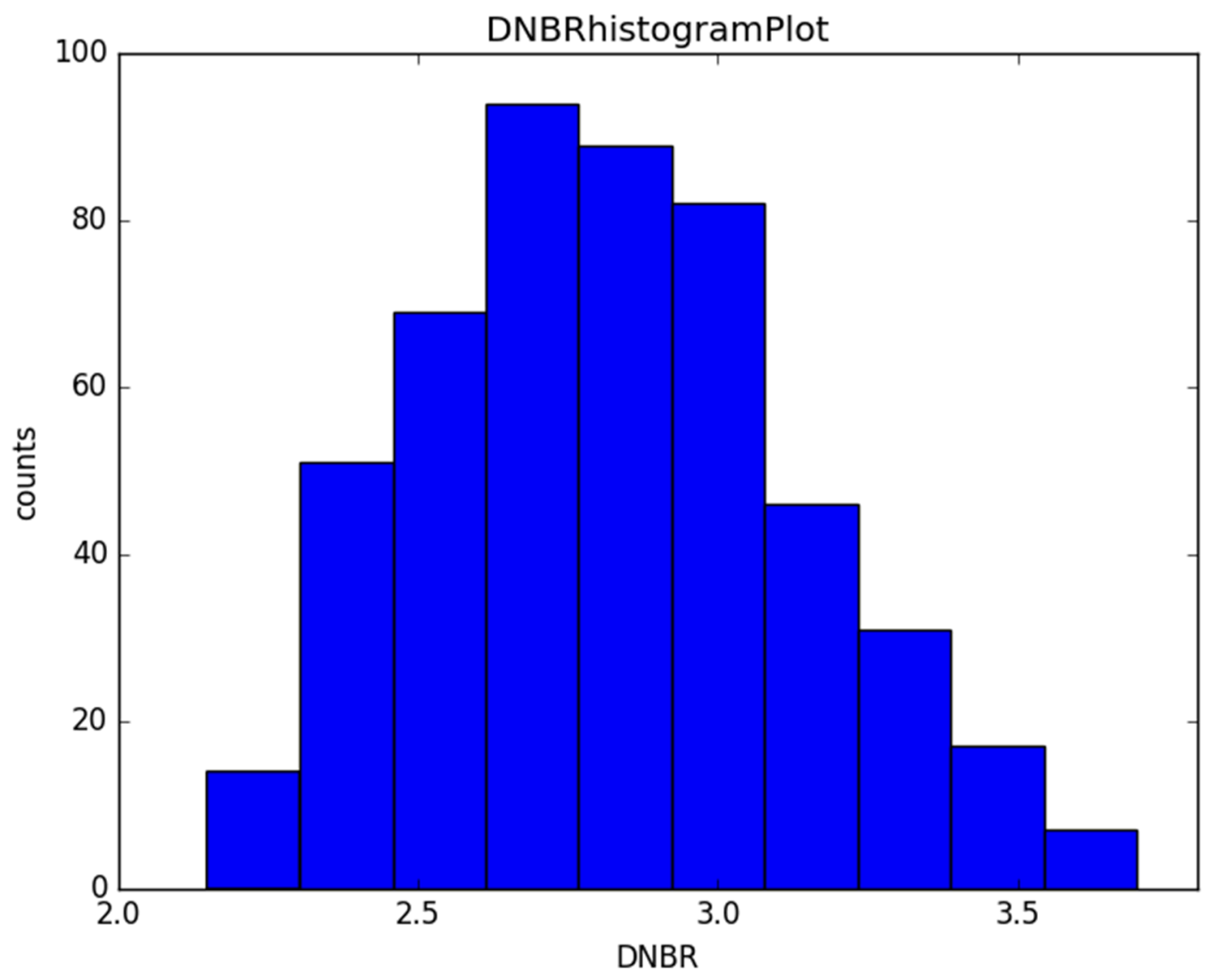

Figure 6. Histogram of DNBR at the Time of Minimum DNBR in the FSP-1 experiment. 


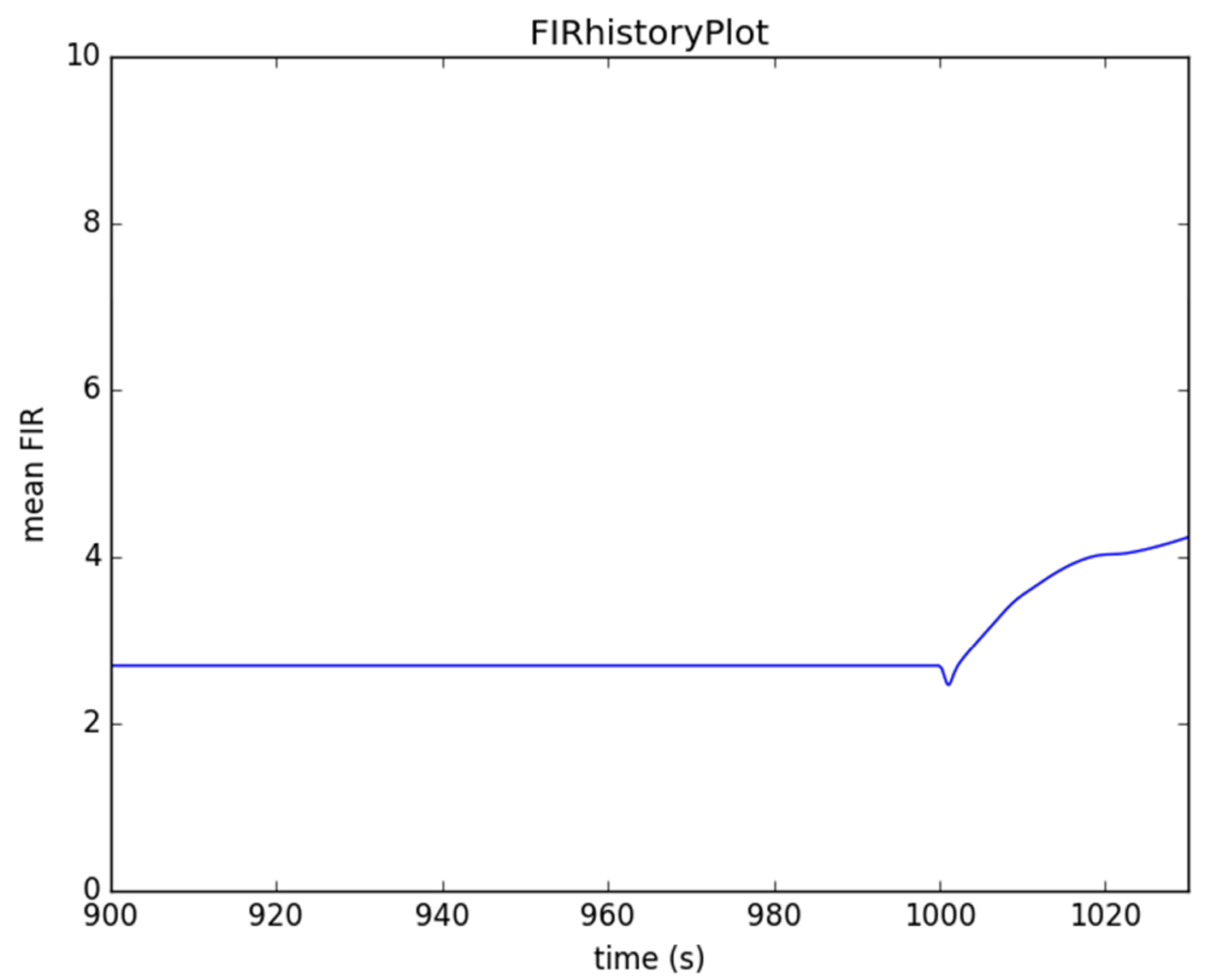

Figure 7. Time History of the Mean Value of FIR in the FSP-1 experiment. 


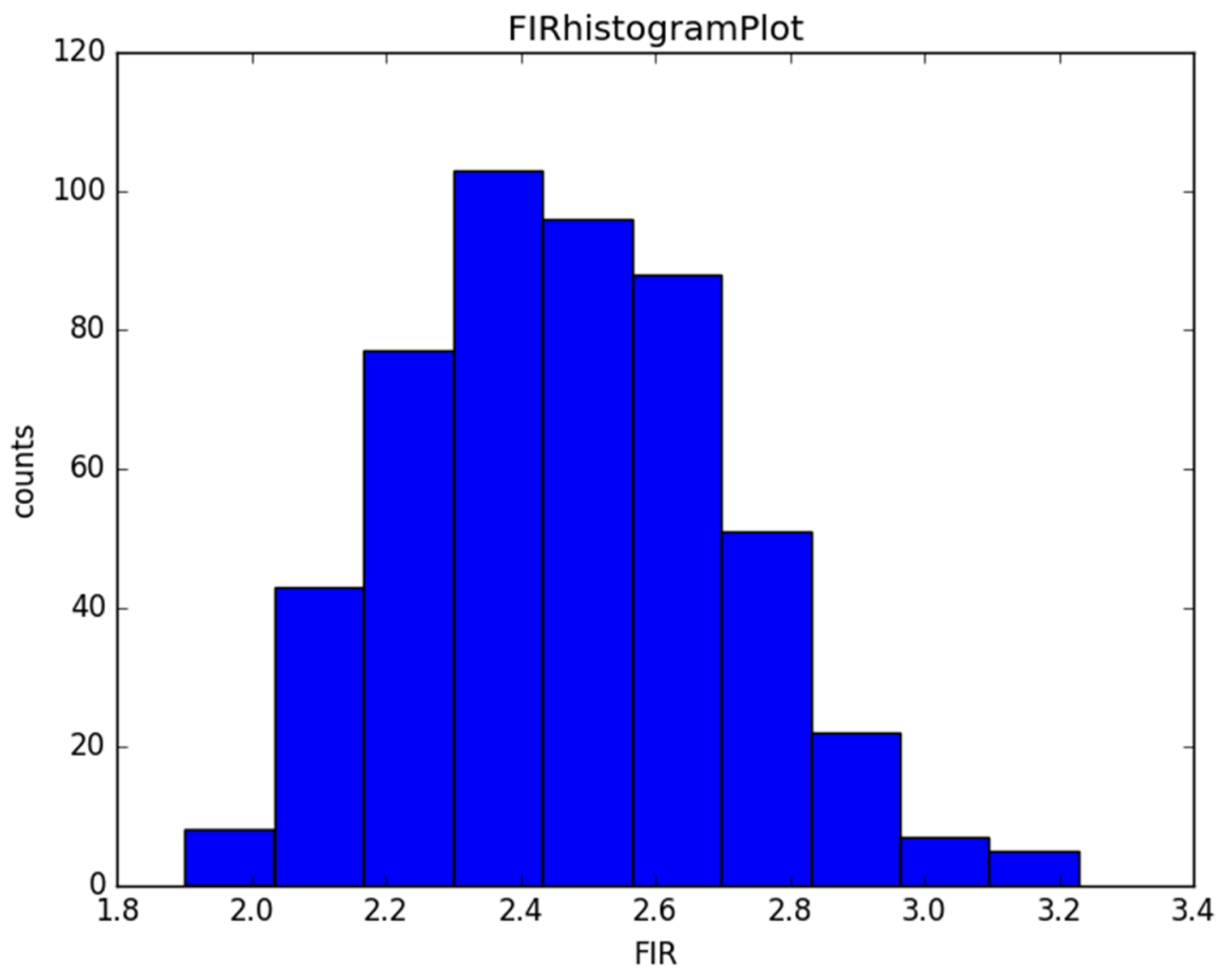

Figure 8. Histogram of FIR at the Time of Minimum FIR in the FSP-1 experiment. 
Table 2. Statistical Analysis of the Output Parameters in the FSP-1 experiment.

\begin{tabular}{|l|l|l|}
\hline Parameter & Mean & $\begin{array}{l}\text { Standard } \\
\text { Deviation }\end{array}$ \\
\hline mass flux $(\mathrm{kg} / \mathrm{s})$ & 19.57 & 1.18 \\
\hline pressure $(\mathrm{MPa})$ & 2.04 & 0.0178 \\
\hline quality & -0.275 & 0.0104 \\
\hline heat flux $\left(\mathrm{MW} / \mathrm{m}^{2}\right)$ & 7.21 & 0.596 \\
\hline cladding temperature $\left({ }^{\circ} \mathrm{K}\right)$ & 489 & 12.3 \\
\hline $\mathrm{CHF}\left(\mathrm{MW} / \mathrm{m}^{2}\right)$ & 20.19 & 0.637 \\
\hline DNBR & 2.82 & 0.307 \\
\hline coolant temperature $\left({ }^{\circ} \mathrm{K}\right)$ & 389 & 6.18 \\
\hline saturation temperature $\left({ }^{\circ} \mathrm{K}\right)$ & 483 & 0.034 \\
\hline FIR & 2.47 & 0.238
\end{tabular}




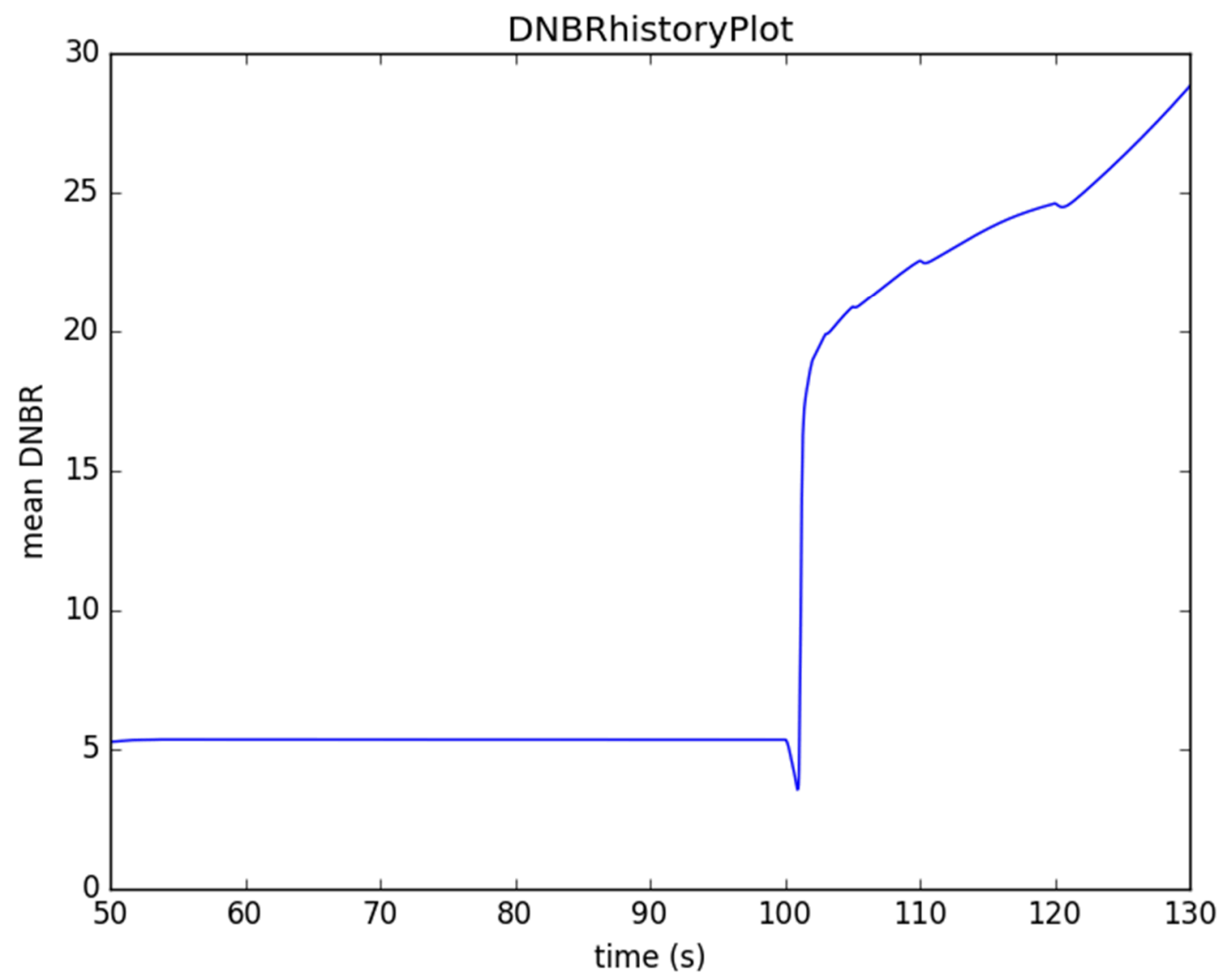

Figure 9. Time History of the Mean Value of DNBR in the AFIP-6 experiment. 


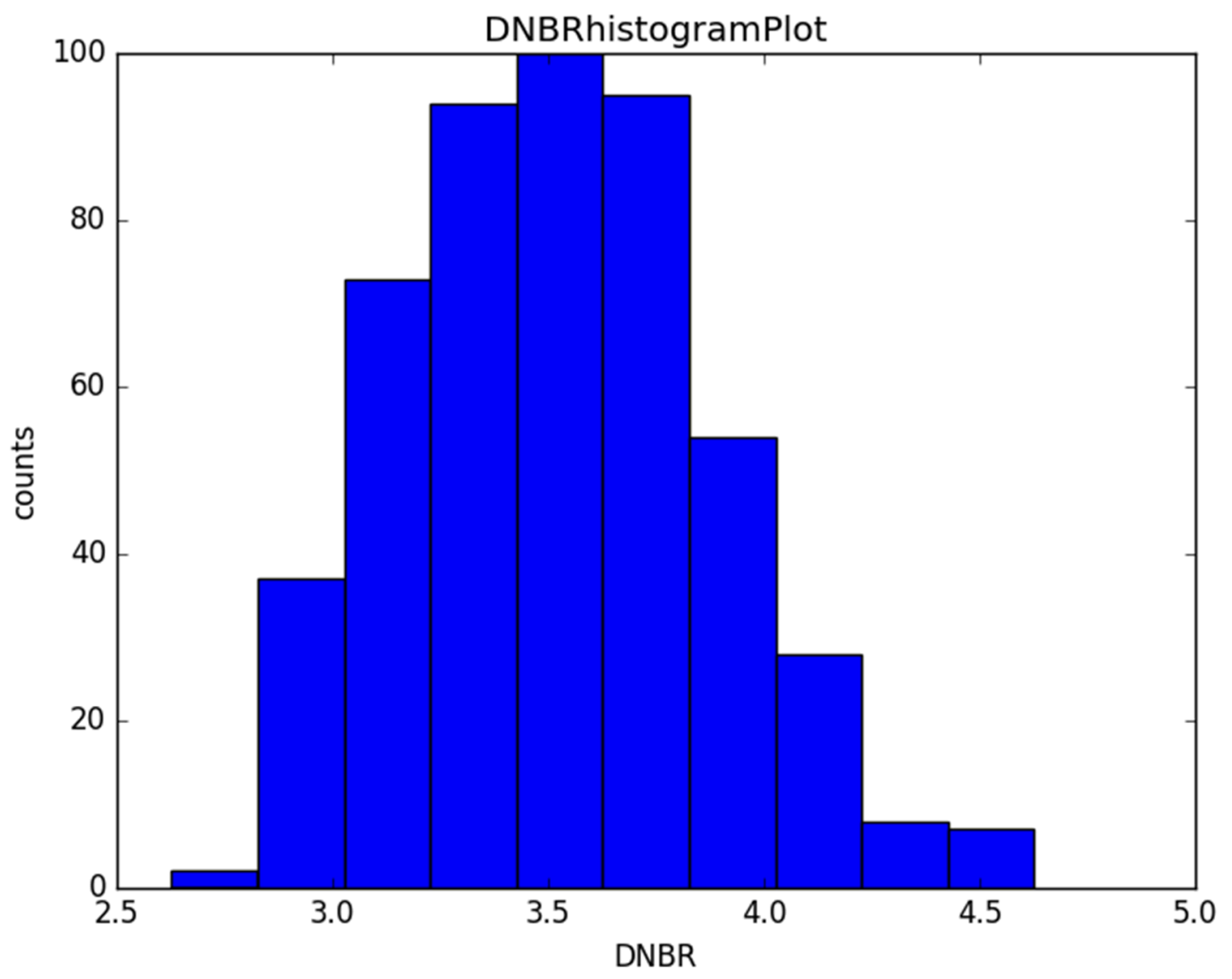

Figure 10. Histogram of DNBR at the Time of Minimum DNBR in the AFIP-6 experiment. 


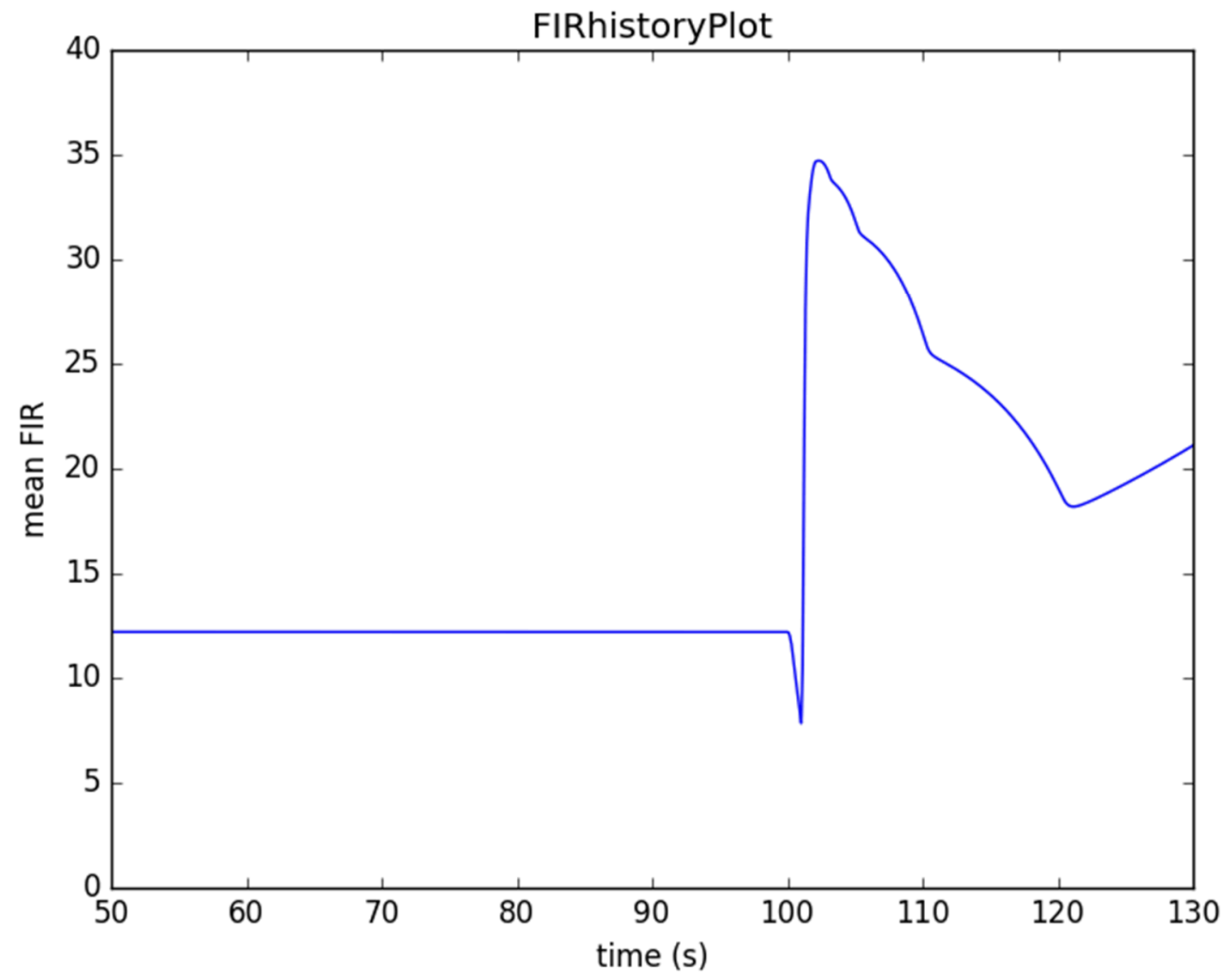

Figure 11. Time History of the Mean Value of FIR in the AFIP-6 experiment. 


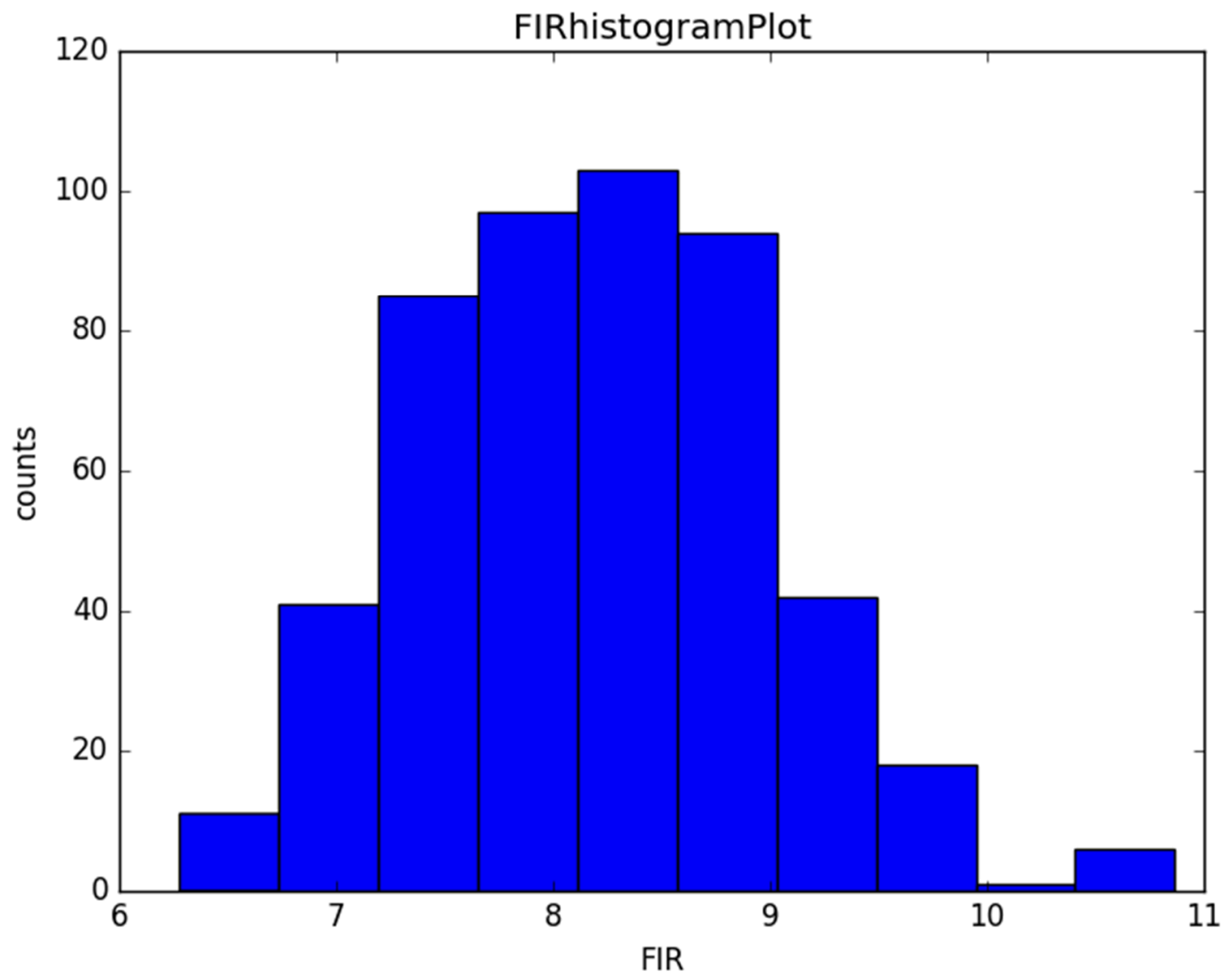

Figure 12. Histogram of FIR at the Time of Minimum FIR in the AFIP-6 experiment. 
Table 3. Statistical Analysis of the Output Parameters in the AFIP-6 experiment.

\begin{tabular}{|l|l|l|}
\hline Parameter & Mean & $\begin{array}{l}\text { Standard } \\
\text { Deviation }\end{array}$ \\
\hline mass flux $(\mathrm{kg} / \mathrm{s})$ & 3.42 & 0.196 \\
\hline pressure $(\mathrm{MPa})$ & 1.95 & 0.00707 \\
\hline quality & -0.334 & 0.00286 \\
\hline heat flux $\left(\mathrm{MW} / \mathrm{m}^{2}\right)$ & 10.6 & 0.878 \\
\hline cladding temperature $\left({ }^{\circ} \mathrm{K}\right)$ & 494 & 11.9 \\
\hline $\mathrm{CHF}\left(\mathrm{MW} / \mathrm{m}^{2}\right)$ & 37.1 & 1.57 \\
\hline DNBR & 3.53 & 0.356 \\
\hline coolant temperature $\left({ }^{\circ} \mathrm{K}\right)$ & 344 & 1.87 \\
\hline saturation temperature $\left({ }^{\circ} \mathrm{K}\right)$ & 482 & 0.141 \\
\hline FIR & 8.19 & 0.790
\end{tabular}




\section{SUMMARY}

In summary, the resulting safety margins given by equations (1) and (2) are conservative since the individual events leading to the cumulative safety factor are assumed to occur simultaneously at their maximum uncertainty. Therefore, an uncertainty analysis was performed to reduce the conservatism resulting from an overabundance of safety factors. The uncertainty analysis was performed using RAVEN and RELAP5 to determine the mean and standard deviation of the calculated safety margins. Rather than requiring that DNBR $>2$ and FIR $>2$, an uncertainty analysis was used to show that the statistical criteria for DNB and FI safety margins given by equations (4) and (5) are met. The statistical criteria are less conservative in the case where the uncertainties are not too large, and may expand the operating envelope of ATR experiments by enabling irradiation of fueled experiments at higher heat flux.

\section{REFERENCES}

RELAP5-3D Code Manual, INL/MIS-15-36723, Revision 4.3, October 2015.

RAVEN Theory Manual and User Guide, INL/EXT-16-38178, Revision 2, March 2017.

SAR-153-10, Chapter 10 - Experiment and Irradiation Facilities - Upgraded Final Safety Analysis Report for the Advanced Test Reactor, Revision 28, September 19, 2018.

D. C. Groeneveld et al., The 2006 CHF lookup table, Nuclear Engineering and Design 237, 1909-1922, 2007.

ECAR-3078, Loss of Commercial Power Accident Including the Effects of Reactivity Insertion from the Experiment Loops, Revision 1, October, 2016.

TRA-ATR-840, ATR-SINDA and SINDA-SAMPLE Calculations for Chapter 15 of the ATR's Updated SAR, Revision 0, February, 1994.

ECAR-1641, AFIP-6 MK II Thermal Analysis, Revision 0, September 2011.

ECAR-2677, Thermal Analysis of the FSP-1 Experiment, Revision 1, June 2016.

ECAR-2975, Thermal Analysis of the MP-1 High Power and Medium Power Experiments, Revision 0, August 2016.

\section{ACKNOWLEDGEMENTS}

This work was supported by the INL LDRD project 17A1-105FP Safety Margin Evaluation for Experiment Irradiation in ATR. 